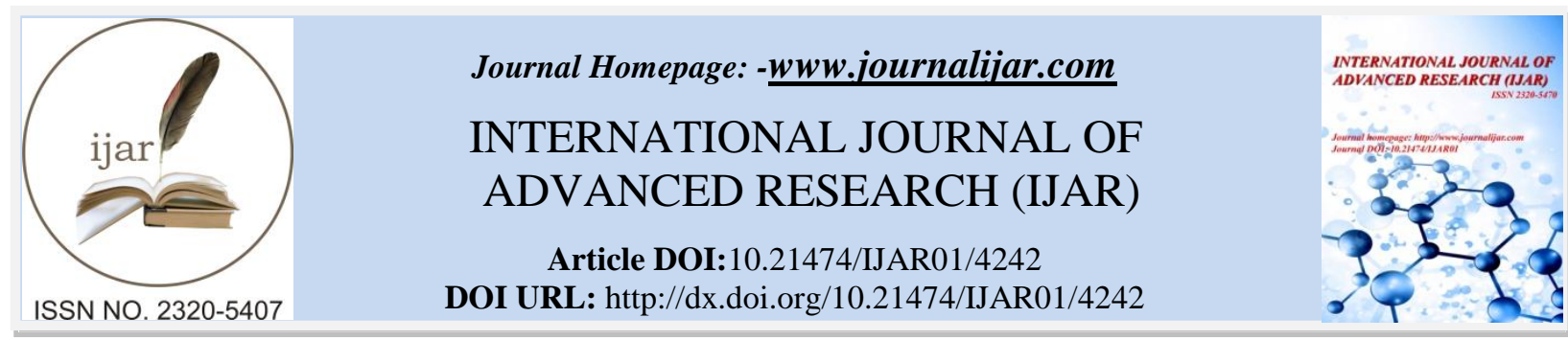

RESEARCH ARTICLE

\title{
PRELIMINARY STUDY OF GLYCEROL ESTER USAGE AS PRIMARY AND SECONDARY EMULSIFIER ON OIL BASED MUD FORMULATION.
}

\author{
Vonny Indah Sari ${ }^{1}$, Erliza Hambali ${ }^{1,2}$, Ani Suryani ${ }^{1,2}$, Pudji Permadi ${ }^{2,3}$. \\ 1. Post Graduate Program of Agroindustrial Technology, Bogor Agricultural University, Bogor 16680, West Java, \\ Indonesia. \\ 2. Surfactant and Bioenergy Research Center, LPPM-IPB, Padjajaran Street, Bogor 16153, Indonesia. \\ 3. Program Study of Oil Engineering, Bandung Institute of Technology, Bandung, Indonesia.
}

\section{Manuscript Info}

Manuscript History

Received: 23 March 2017

Final Accepted: 25 April 2017

Published: May 2017

Key words:-

glycerol esters, oil based mud (OBM), primary emulsifier, secondary emulsifier

\begin{abstract}
Glycerol ester is a glycerol derivative product as more value-added byproduct of biodiesel industry. Glycerol ester is obtained by esterification reaction between glycerol and palm oil oleic acid with the addition of methyl ester sulfonic acid (MESA) as catalyst. Glycerol ester is palm oil derivative which is not toxic and renewable. One potential use of glycerol esters is as one components of oil-based formulation for petroleum drilling needs as emulsifier substitute. Emulsifier in drilling mud formulations serves to produce a stable emulsion between oil and water. Emulsifier in drilling fluid formulations commonly used come from petroleum derivatives that non-renewable and expensive. To be used as emulsifier substitute in drilling fluid formulations, glycerol esters must provide test results that are not significantly different from emulsifier derived from petroleum. The purpose of this study is to obtain glycerol ester concentration that will be added in the formulation as emulsifier substitute material in drilling fluids formulation for oil drilling. The concentration of glycerol ester added is as much as $5 \mathrm{lb} / \mathrm{bbl}$, $10 \mathrm{lb} / \mathrm{bbl}, 15 \mathrm{lb} / \mathrm{bbl}$ and 20lb/bbl. Tests on the formulation is include density, viscosity, gel strength, plastic viscosity, yield point, electrical stability, oil water ratio, excess lime, the percentage of water and oil, and HPHT filtrate at temperatures of $350{ }^{\circ} \mathrm{F}$ and pressure of $650 \mathrm{psi}$. The analysis showed that the best test for blanko is glycerol ester with a concentration of $5 \mathrm{lb} / \mathrm{bbl}$. The results are expected to be used as an alternative to substitute the emulsifier derived from petroleum with emulsifier from palm oil.
\end{abstract}

Copy Right, IJAR, 2017,.All rights reserved.

\section{Introduction:-}

Glycerol ester is a carboxylic acid derivative resulting from glycerol esterification with fatty acids. Glycerol ester is an ester compound with glycerol as the alcohol molecules. In some soybeans producer countries, glycerol as byproduct of soybean biodiesel is being developed as drilling fluid for oil well drilling needs. The nature and lubricating emulsion of glycerol derivate is used to improve the quality of oil drilling mud as formulation material for water-based mud (WBM). Glycerol that used in WBM drilling fluid has some disadvantage, among others, are not stable at high temperatures and is easy to cause swelling (Soares et al. 2011; Westfechtelet al. 2012). Drilling 
fluid or drilling mud is mud fluid made from mixing of liquids, solids and chemicals substance with their respective functions. Drilling mud is an important factor and crucial in supporting the success of a drilling operation. Drilling speed, efficiency, safety and cost is depends on drilling mud performance. The advantage of oil-based drilling mud, among others are stable at high temperatures, suitable for deep sea drilling zone, has good lubrication properties and does not cause corrosion on drilling equipment. Meanwhile, the disadvantage is not environmental friendly and relatively expensive (Hou et al. 2003; Ryen 2011: Emmanuella et al. 2010).

This study uses oleic glycerol ester of palm oil as emulsifier substitution material in drilling fluid. Esterification between glycerol and oleic acid can produce mono oleate glycerol, dioleate glycerol and trioleate glycerol (Pouilloux et al. 1998; Noureddini et al. 2012). Oleic ester glycerol is yellow liquid with sufficient high viscosity, odorless, non-toxic, insoluble in water, soluble in oil, ether and petroleum ether (Othmer 1990). Oleic ester glycerol havephysico-chemical properties that suitable for the use as drilling fluid formulation material as formulation substitution material derived from petroleum, among others, have high flash point and melting point that make stable on drilling that requires high temperatures (Kendel 2012)

Glycerol ester as an emulsifier substitution substance of bio oils is expected to have properties in accordance with emulsifier derived from petroleum derivatives and provide good test results. This study found the best concentration of glycerol ester as emulsifier substitution in oil-based drilling fluid formulations. The main component of oil-based drilling fluid is oil, water, $\mathrm{CaCl}_{2}$, viscosifier, fluid loss control, lime, ballast material, primary emulsifiers, secondary emulsifiers and wetting agent. Primary emulsifier is more work to allow the dispersion of the two fluids to form internal and external phase. While the secondary emulsifier act more as a wetting agent to maximize the function of viscosifier in formulation.

\section{Materials and Methods:-}

Materials and Tools:-

The tools used is consisted of measuring and testing tools, such as mud balance pressurized, Fann Viscometer, retort kit, High Pressure High Temperature Filter Press, oven hot roller and aging cell. Chemicals substance for testing are $\mathrm{AgNO}_{3}, \mathrm{H}_{2} \mathrm{SO}_{4}$, potassium chromate, propanol, xylene and distilled water.

The materials used is glycerol ester as derived glycerol of biodiesel production byproduct, obtained from the Surfactant and Bioenergy Research Center (SBRC) - LPPM-IPB. The additive materials used were taken from some well known products and commonly used in drilling operations and meets the requirements of API. Material selection is based on the design of the mud formulations.

\section{Methods:-}

The study began with preparation of glycerol ester from glycerol of biodiesel industrial byproducts that have been purified. This study was conducted with testing at laboratory scale. Characteristics of glycerol as drilling fluid formulation material can be seen in Table 1. The first stage of the research is prepare drilling mud formulation (blank) that adapted to field conditions using the materials in accordance with API standards (Table 2). Then, blanks parameters formulation is tested as benchmark for mud formulation test. The next stage is prepare formulations using glycerol ester as primary and secondary emulsifiers (Table 3 and Table 4) and tested as the blank formulation. The experimental design is non factorial completely randomized design with two replications. The concentration of glycerol ester as emulsifier is F1 = $5 \mathrm{lb} / \mathrm{bbl}, \mathrm{F} 2=10 \mathrm{lb} / \mathrm{bbl}, \mathrm{F} 3=15 \mathrm{lb} / \mathrm{bbl}$ and F4 = $20 \mathrm{lb} / \mathrm{bbl}$.

Table 1:-Physico-chemical properties of glycerol ester

\begin{tabular}{|l|c|}
\hline Properties & Value \\
\hline Total glycerol content $(\%)$ & 1,77 \\
\hline Acid Number $(\mathrm{mg} \mathrm{KOH} / \mathrm{g}$ unit $)$ & 1,90 \\
\hline Flash Point $\left({ }^{\circ} \mathrm{C}\right)$ & 241 \\
\hline Density g/Cm & 0,94 \\
\hline Kinematic viscosity $\left(\mathrm{cSt} ; 40^{\circ} \mathrm{C}\right)$ & 31,51 \\
\hline Pour point $\left({ }^{\circ} \mathrm{C}\right)$ & -3 \\
\hline Boiling point $\left({ }^{\circ} \mathrm{C}\right)$ & 244 \\
\hline Surface Tension $\left(30^{\circ} \mathrm{C}\right)$ & 37,0526 dyne $/ \mathrm{cm}$ \\
\hline
\end{tabular}


Testing parameter of mud formulations is rheology properties testing such as plastic viscosity, yield point and gel strength, physical properties testing such as mud density, HPHT filtration loss, oil water ratio (OWR), Emulsion stability (ES), solid content and water phase salinity (WPS). All the testing is based on the American Petroleum Institute standard (API 2005).

Table2:- Drilling Mud Formulation (blank)

\begin{tabular}{|l|c|c|c|c|}
\hline Material & $\begin{array}{c}\text { Mixing } \\
\text { Procedure }\end{array}$ & $\begin{array}{c}\text { Density } \\
(\text { S.G })\end{array}$ & $\begin{array}{c}\text { Lb/bbl } \\
\text { Mixing Time } \\
\text { (minute) }\end{array}$ \\
\hline Base oil & 1 & 0,8 & 179,23 & 3 \\
\hline Emulsifier primary & 2 & 0,95 & 5 & 3 \\
\hline Emulsifier secondary & 3 & 0,95 & 5 & 3 \\
\hline Hydrate lime & 4 & 2,2 & 12 & 3 \\
\hline Filtration control & 5 & 2,2 & 10 & 6 \\
\hline Salinity control & 6 & 2,17 & 22 & \multirow{2}{*}{10} \\
\hline Water & 7 & 1 & 63,19 & 10 \\
\hline Viscosifier & 8 & 2,4 & 7 & 3 \\
\hline Weighting Agent & 9 & 4,2 & 100 & 5 \\
\hline High speed & 9 & & \\
\hline
\end{tabular}

Table3:- Formulation of drilling mud with glycerol ester as primary emulsifier substitution

\begin{tabular}{|l|c|c|c|}
\hline \multicolumn{1}{|c|}{ Material } & $\begin{array}{c}\text { Density } \\
\text { (S.G) }\end{array}$ & Quantity & Mixing Duration (minute) \\
\hline Base oil & 0,8 & 179,23 & 3 \\
\hline Primary emulsifier & 0,95 & $5,10,15,20$ & 3 \\
\hline Secondary emulsifier & 0,95 & 5 & 3 \\
\hline Hydrate lime & 2,2 & 12 & 6 \\
\hline Filtration control & 2,2 & 10 & 10 \\
\hline Salinity Control & 2,17 & 22 & 10 \\
\hline Water & 1 & 63,19 & 3 \\
\hline Viscosifier & 2,4 & 7 & 5 \\
\hline Weighting Agent & 4,2 & 100 & \\
\hline High Speed & \multicolumn{2}{|c|}{} \\
\hline
\end{tabular}

Table4:- Formulation of drilling mud with glycerol ester as secondary emulsifier substitution

\begin{tabular}{|l|c|c|c|}
\hline \multicolumn{1}{|c|}{ Material } & $\begin{array}{c}\text { Density } \\
\text { (S.G) }\end{array}$ & Quantity & Mixing Duration (minute) \\
\hline Base oil & 0,8 & 179,23 & 3 \\
\hline Primary emulsifier & 0,95 & 5 & 3 \\
\hline Secondary emulsifier & 0,95 & $5,10,15,20$ & 3 \\
\hline Hydrate lime & 2,2 & 12 & 3 \\
\hline Filtration control & 2,2 & 10 & 10 \\
\hline Salinity Control & 2,17 & 22 & 10 \\
\hline Water & 1 & 63,19 & 3 \\
\hline Viscosifier & 2,4 & 7 & 5 \\
\hline Weighting Agent & 4,2 & 100 & 2 \\
\hline High Speed & \multicolumn{2}{|c|}{} \\
\hline
\end{tabular}

\section{Result and Discussion:-}

\section{Result of Blank Formulation Test:-}

Mud formulations design were made to be used up to temperature $350^{\circ} \mathrm{F}$. the mud then heated in oven hot roller for 16 hours at temperature of $350^{\circ} \mathrm{F}$. Blank formula is primary and secondary emulsifier derived from petroleum derivatives in accordance with the API standards (API 2004; API 2005). Results of blank formulation test are required as benchmark in formulating the mud with substitution emulsifier using glycerol ester of palm oil 
derivatives. The concentration of glycerol esters made changes while other materials are fixed. Then, testing will be conducted on formulation of mud produced.

\section{Mud Density:-}

Mud density is very important mud properties due to the function to retain formation pressure. Density is a physical mud property to hold the formation pressure to prevent blow-outs and break down formation. The results showed that the density of blank drilling mud formulation generate value 1,16 while the use of glycerol ester as emulsifier is 1.17 to 1.175 or 9.66 ppgto 9.788 ppg. Comparison of mud density between blank formulations and glycerol ester formulation for primary and secondary emulsifiers can be seen in Figure 1.

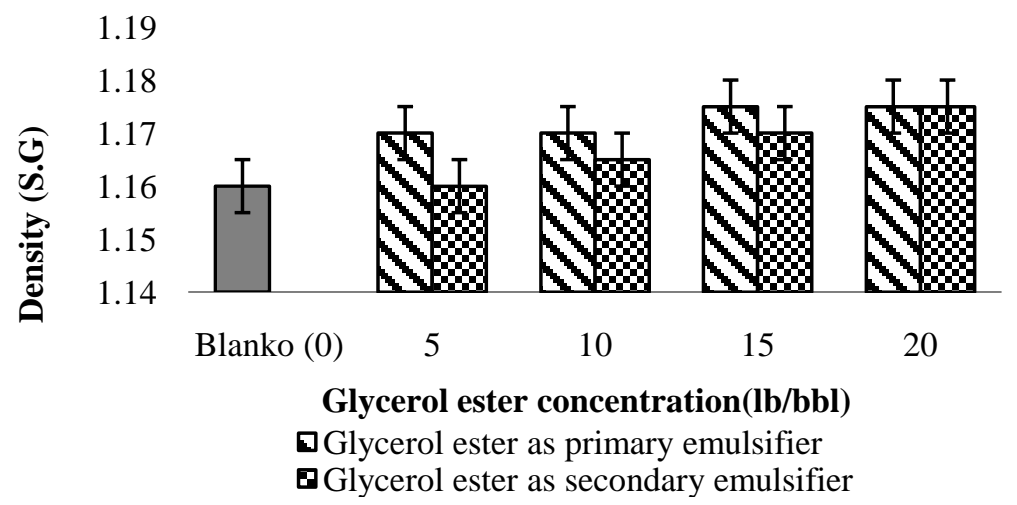

Figure 1:- Relationship between glycerol ester on mud density

The figure above shows that for primary emulsifier, there is an increased of mud density at glycerol ester concentration $5 \mathrm{lb} / \mathrm{bbl}$, and static at concentration $10 \mathrm{lb} / \mathrm{bbl}, 15 \mathrm{lb} / \mathrm{bbl}$ and $20 \mathrm{lb} / \mathrm{bbl}$. Based on the analysis of variance $(\alpha=0.05)$, increasing concentration of glycerol ester significantly affect the mud density mud compared to blank formulation. Result of Duncan test showed that increasing concentration of glycerol ester as primary emulsifier does not have significant effect on the increase in mud density. As secondary emulsifier, increasing of glycerol ester concentration at $5 \mathrm{lb} / \mathrm{bbl}$ and $10 \mathrm{lb} / \mathrm{bbl}$ has no significant effect on the mud density, whereas at 15 $\mathrm{lb} / \mathrm{bbl}$ and $20 \mathrm{lb} / \mathrm{bbl}$ has significant effect on the density. It can be concluded that overall the addition of glycerol ester concentration does not give significantly different effect on the value of mud density. This is because the density of the drilling mud is affected by the amount of ballast additive substances (barite) and the addition of glycerol ester as emulsifier must in large numbers if the purpose is to increase the mud density. Design of drilling mud formula must be have hydrostatic pressure greater than the formation pressure,namely $2 \%$ to $10 \%$ (Adam \& Neal 1985; API 2003; Baker 1995). It is intended to reduce the risk of loss circulation, kick, and even blow out on oil drilling process in the field. Too large drilling mud density will cause the mud lost to the formation (lost circulation) and the decrease of drilling rate, while too small will cause the formation fluids influx into the wellbore. The increased of mud formulations density is because glycerol ester density is sufficiently high to affect the mud density.

\section{Mud Rheology Properties:-}

Determination of mud rheology at high pressure high temperature conditions aimed to study the behavior of the mud to temperature changing. Mud rheology properties is including plastic viscosity value (PV), yield point (YP) and the gel strength. Plastic viscosity (PV) is a measure of the resilience of the drilling mud fluid to flow. Its value obtained from subtraction of dial reading at $600 \mathrm{rpm}$ on the dial reading at $300 \mathrm{rpm}$. Yield point is the ability of the mud fluid to lift the cutting. Yield point (YP) value is obtained from subtraction of PV value to dial reading at $300 \mathrm{rpm}$. The unit of $\mathrm{YP}$ is $\mathrm{lb} / 100 \mathrm{ft}^{2}$. Gel strength is the ability of the drilling mud to hold the cutting in static conditions. The value of PV, YP and gel strength for blank and glycerol ester as primary and secondary emulsifiers can be seen in Figure 2, Figure 3, Figure 4 and Figure 5 below. 


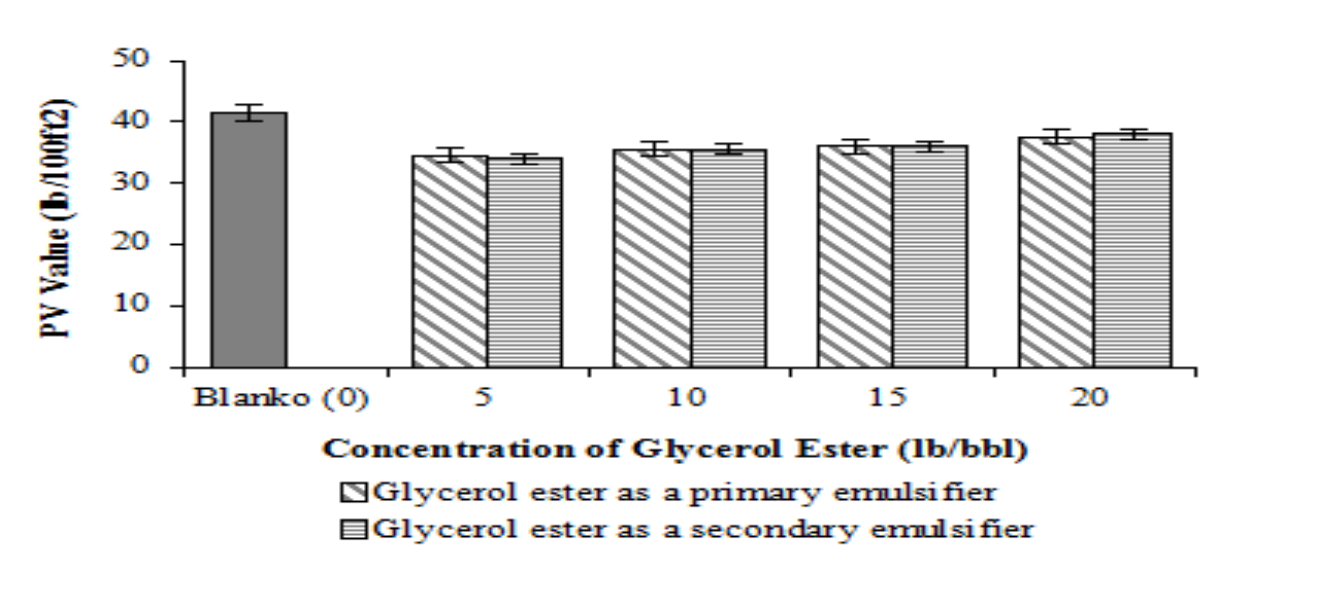

Figure 2:- Relationship between glycerol ester concentration and PV value of mud

The figure above show that the value of mud PV using glycerol esters ranges between $27-38 \mathrm{cP}$ and the value is smaller when compared to the blank. Based on the analysis of variance $(\alpha=0.05)$ and Duncan test, concentration of glycerol ester as primary and secondary emulsifier is not significantly different from the blank formulations of the PV value generated. PV value is influenced by the solids content, the size of the solids and temperature. The decline in PV value in formulations using glycerol ester is likely due to temperature effect when PV measurement performed where the viscosity of glycerol esters will decrease as the temperature increases. Overall the PV value obtained is still within the required range. Plastic viscosity affects the performance of mud on the formation. If too high will lead to decline in the rate of drilling and high pressure loss due to friction and hard to release gas and cutting in surface. Whereas, if too low the lifting of cutting becomes less good (Moore 1974).

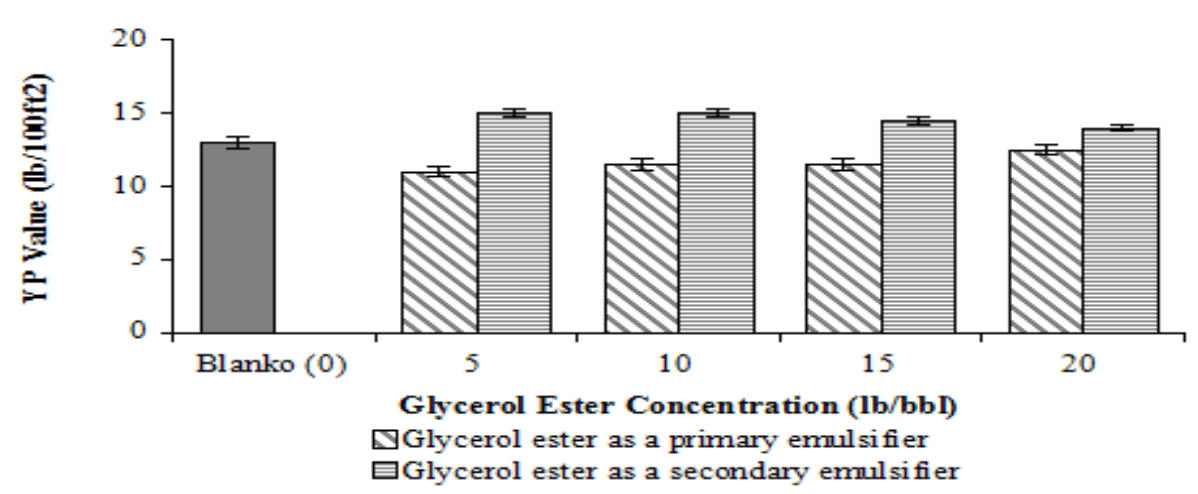

Figure 3:- Relationship between glycerol ester concentration and YP value

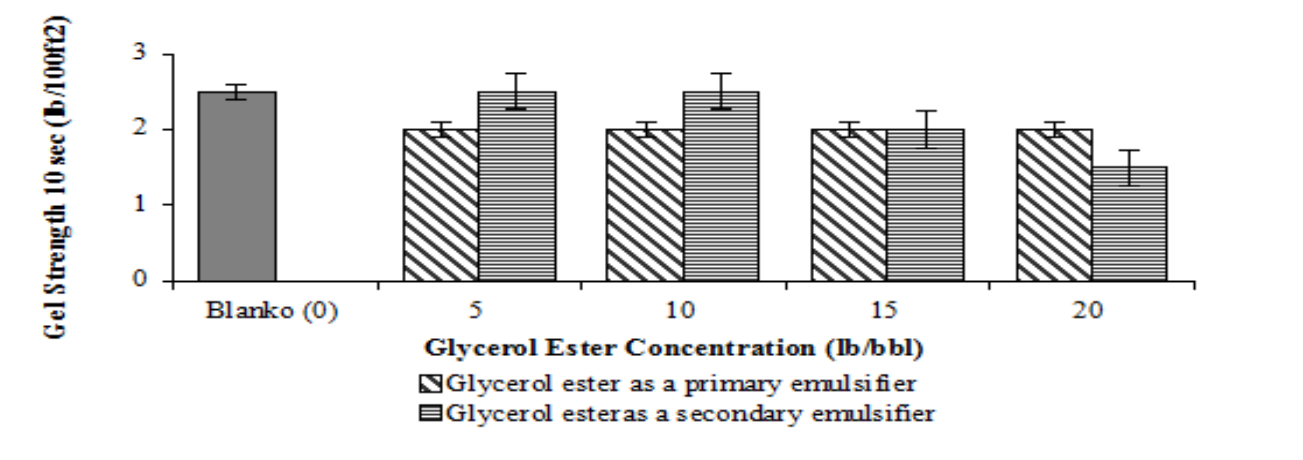

Figure 4:- Relationship between glycerol ester concentration and Gel Strength 10" 


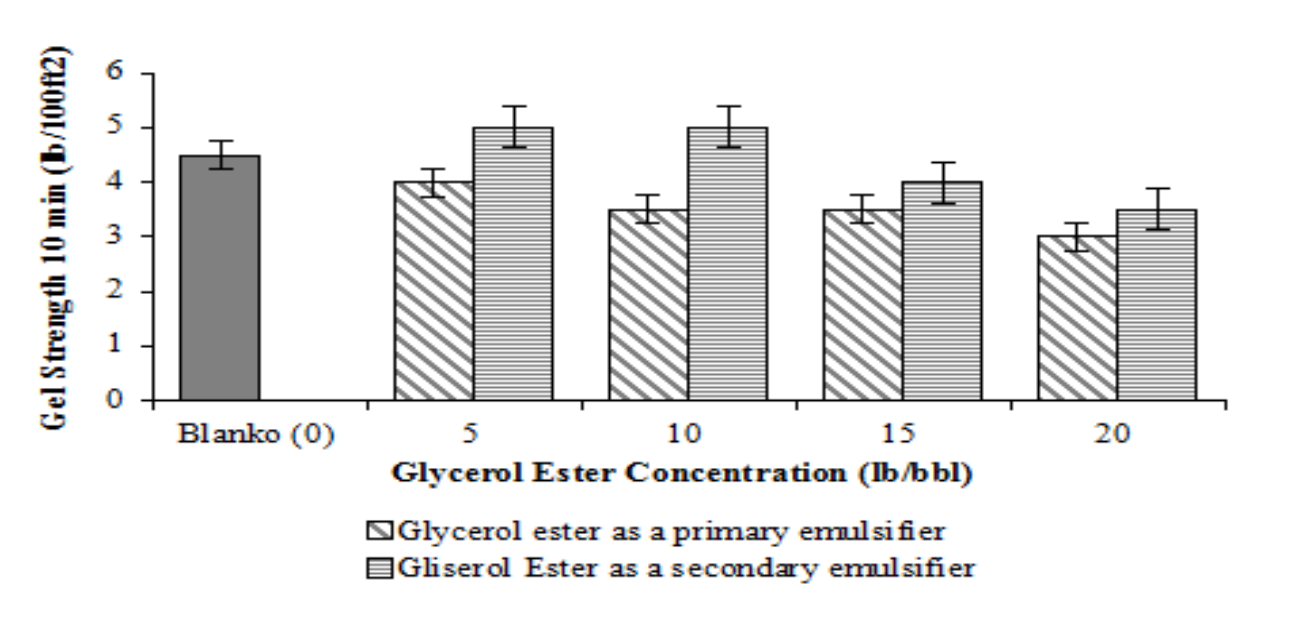

Figure 5:- Relationship between glycerol ester concentration and Gel Strength 10’

The value of YP formulations decrease after using glycerol ester as primary emulsifier, but the value of YP increases with increasing concentrations of glycerol ester. Based on the analysis of variance, the increased concentration does not give a significant effect on the value of YP drilling mud at level of significance 0.05. Substitution of glycerol ester as a secondary emulsifier shows an increase in YP value compared to the blank, but the value decline with increasing concentrations of glycerol ester formulations. Increasing of YP value of glycerol ester formulations does not deviate much from the value of the benchmark. As evidenced by Duncan Test, increased concentration of glycerol esters do not provide a significantly different effect on the mud YP value at 0.05 . Yield point is a number that indicates the shearing stress necessary for re-circulating the mud. Mud will not flow before shearing stress given at the yield point. The increase in yield point will affect the hydraulics of the drilling mud system and cause mud pump works harder. Both yield point and gel strength is a measure of the gravitational pull in a mud system. The difference is gel strength is in static state while YP in dynamic state. Yield point is must be known because affect on the pressure loss of circulation (Moore 1974; Baker 1995).

Gel strength is a measure of colloidal dispersions ability to maintain the jelly shape and solids formation due to the attractive forces among clay molecules in static state. By the time, the gel strength will increase. From the figure of relationship between increasing glycerol ester concentration with gel strength value, it can be seen that the primary emulsifier to gel strength at 10 seconds and 10 minutes tend to decrease thank blank formulation, while for secondary emulsifier, at the gel strength 10 seconds tends to decrease with increasing concentration of glycerol ester but to gel strength 10 minutes at a concentration of $5 \mathrm{lb} / \mathrm{bbl}$ and $10 \mathrm{lb} / \mathrm{bbl}$ increased the gel strength of the blank formulation. Overall the value of gel strength is still within the limits required in the blank formulation as benchmark. Based on Duncan test, glycerol ester concentration has no significant effect on the value of drilling mud gel strength at level of significance 0.05 . Gel strength value affects the performance of the drilling mud. Too low gel strength will cause cutting or sand settled when circulation stops, whereas too large the value will hamper the pump to re-circulating. The nature of mud rheology is related to mud viscosity and density. The increase in rheology properties of the mud formulation with the addition of glycerol ester is possibility due to the high viscosity of glycerol ester thus affecting the rheology properties.

\section{Electrical Stability:-}

Testing of emulsion stability (Electrical Stability) is aimed to determine the stability and the type of emulsion, whether water-in-oil or oil-in-water. Figure 6 shows the effect of glycerol ester addition at various concentrations to the ES meter of drilling mud. The value of electrical stability for glycerol ester as primary emulsifier is 510 to 405 volts and as secondary emulsifier ranged from 500.5 to 400.5 volts. The figure shows that glycerol esters tend to lower the value of ES meters of mud formulations compared to blank ES formulation. The higher the concentration of glycerol ester, the lower of ES values. 


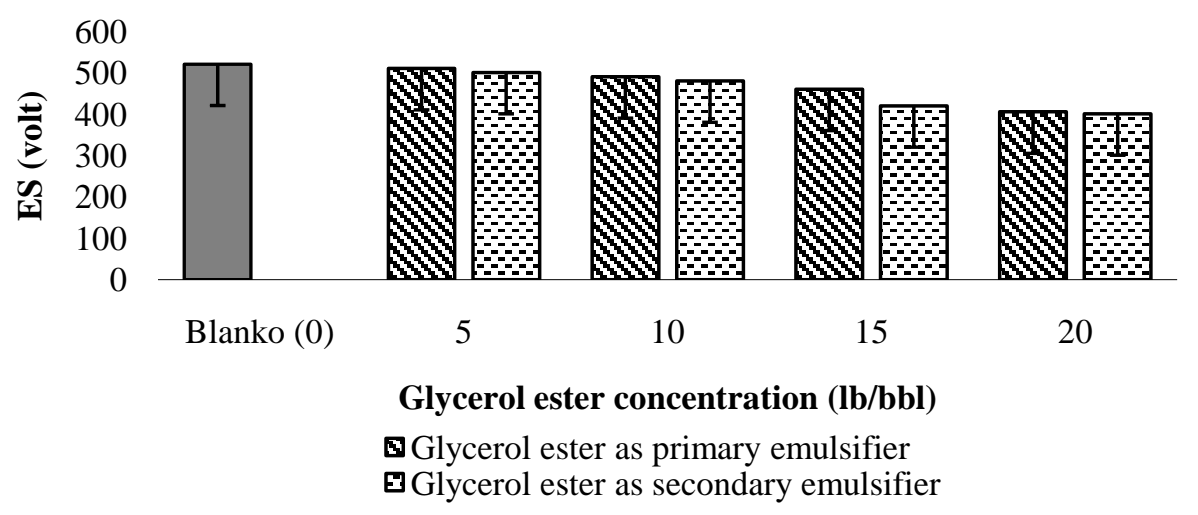

Figure 6:- Relationship between glycerol ester concentrations with ES Meter value

Based on the analysis of variance $(\alpha=0.05)$, the increasing concentration of glycerol ester has significant effect on the ES meter. High ES meter indicates that the emulsion is more stable. The minimum ES value required is 400 volts. The required ES meter is at a concentration of $5 \mathrm{lb} / \mathrm{bbl}, 10 \mathrm{lb} / \mathrm{bbl}$ and $15 \mathrm{lb} / \mathrm{bbl}$ for glycerol ester as primary emulsifier, while all secondary emulsifier not meets with the minimum requirements. Duncan test show that concentration of glycerol ester as primary emulsifier at $5 \mathrm{lb} / \mathrm{bbl}, 10 \mathrm{lb} / \mathrm{bbl}$ and $15 \mathrm{lb} / \mathrm{bbl}$ have no significant effect, but at $20 \mathrm{lb} / \mathrm{bbl}$ has significant effect. Concentrations of glycerol ester as secondary emulsifier at $5 \mathrm{lb} / \mathrm{bbl}, 10 \mathrm{lb} / \mathrm{bbl}$ and $15 \mathrm{lb} / \mathrm{bbl}$ have no significant effect and concentration of $20 \mathrm{lb} / \mathrm{bbl}$ have significant effect.

Decrease in ES on oil-based mud formulation is usually due to brine contamination that is water contamination in the formation. In this study, increased concentrations of glycerol ester lead to decrease in ES value. This can be caused by presence of water content in the glycerol ester used as emulsifier substitute material, causing brine contamination and lower ES value as well as unstable formulation. The higher value of ES indicates water in oil emulsion is more stable. This can be prevented by adding lime additive to the formulation to change the properties of water-wet wet ability because the function of lime is as alkalinity to activate emulsifier.

\section{HPHT Filtrate $\left(350^{\circ} \mathrm{F}, 650 \mathrm{psi}\right):-$}

Filtration loss is loosing of filtrate from liquid component of drilling mud systems that enter to the formation penetrated by matabor. The solid component attached at the borehole wall is called mud cake. The effect of this filtrate is causing formation damage or swelling and reduces the diameter of the drill hole as a result of the mud cake.

Mud is good if produce minimum filtrate to reduce formation damage due to invasion of small zones. This research resulted in filtrate which ranged from 10 to $12.5 \mathrm{ml}$ in glycerol esters as substitutes for primary emulsifier and 10.5 to $13.5 \mathrm{ml}$ of the glycerol ester as a secondary emulsifier substitution. Figure 7 shows the relationship between the addition of glycerol ester as primary and secondary emulsifier to the filtrate produced in the temperature and pressure of $650 \mathrm{psi}$ and $350^{\circ} \mathrm{F}$.

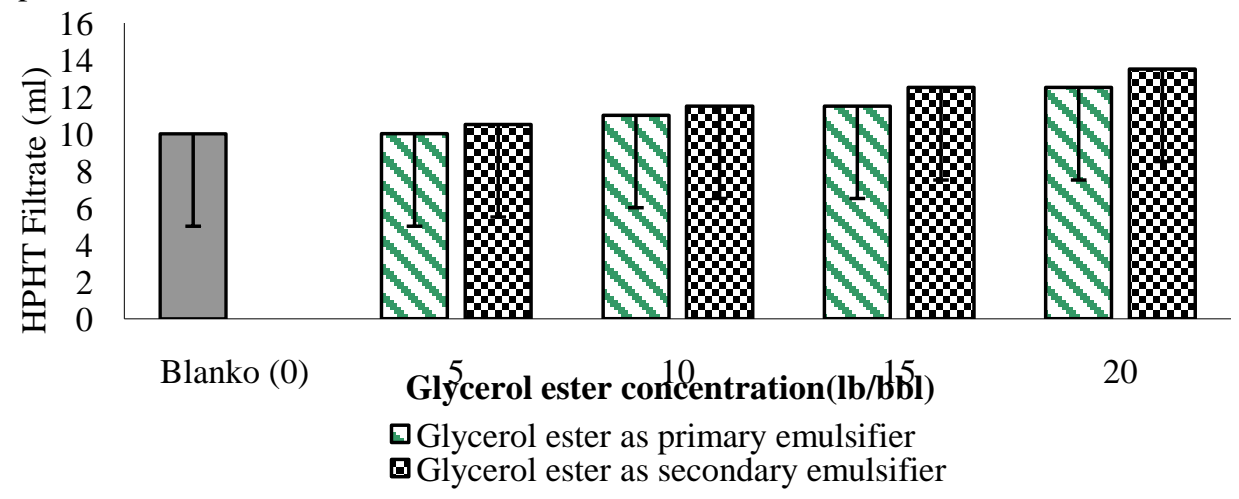

Figure 7:- The relationship between glycerol ester concentration with HPHT Filtrate value 
The figure show that the addition of glycerol ester as primary and secondary emulsifier increase the HPHT filtrate produced. Analysis of variance $(\alpha=0.05)$ show that increasing glycerol ester concentration gives a significantly different effect on the HPHT filtrate produced. Duncan test showed that for primary emulsifier, increasing concentrations of glycerol ester at $5 \mathrm{lb} / \mathrm{bbl}$ is not significantly different from the blank, but significantly different at concentrations $10 \mathrm{lb} / \mathrm{bbl}, 15 \mathrm{lb} / \mathrm{bbl}$ and $20 \mathrm{lb} / \mathrm{bbl}$. For glycerol ester as substitute for secondary emulsifier, concentration at $5 \mathrm{lb} / \mathrm{bbl}$ is not significantly different from the blank. Increasing of glycerol ester concentration at 5 lb/bbl, $10 \mathrm{lb} / \mathrm{bbl}, 15 \mathrm{lb} / \mathrm{bbl}$ and $20 \mathrm{lb} / \mathrm{bbl}$ shows significant effect. To overcome this, the mud must be made with formulations that add some stable filtrate controller additives at high temperatures and pressures such as HT viscosifier or HT stabilizer. Increased HPHT filtrate produced by the addition of glycerol ester as emulsifier substitution may due to the persistence of the water content in glycerol esters that affect the amount of HPHT filtrate produced at the given temperatures and pressures.

\section{Solid Content:-}

Information of solids content of the drilling mud is important to control the good properties of mud. Such information will describe the performance of mud silt indicate whether it should be conditioned by adding water, using chemical thinners, or eliminate certain contaminants. In addition, it is also to control proper ratio of oil/water and water emulsion in oil on oil-based mud. This study shows obtained solids content with the addition of glycerol ester as primary emulsifier ranges between $6 \%-11 \%$ and as secondary emulsifier ranges from $7.5 \%-8 \%$. Figure 9 shows the effect of adding glycerol ester as emulsifier on the solids content of the formulation.

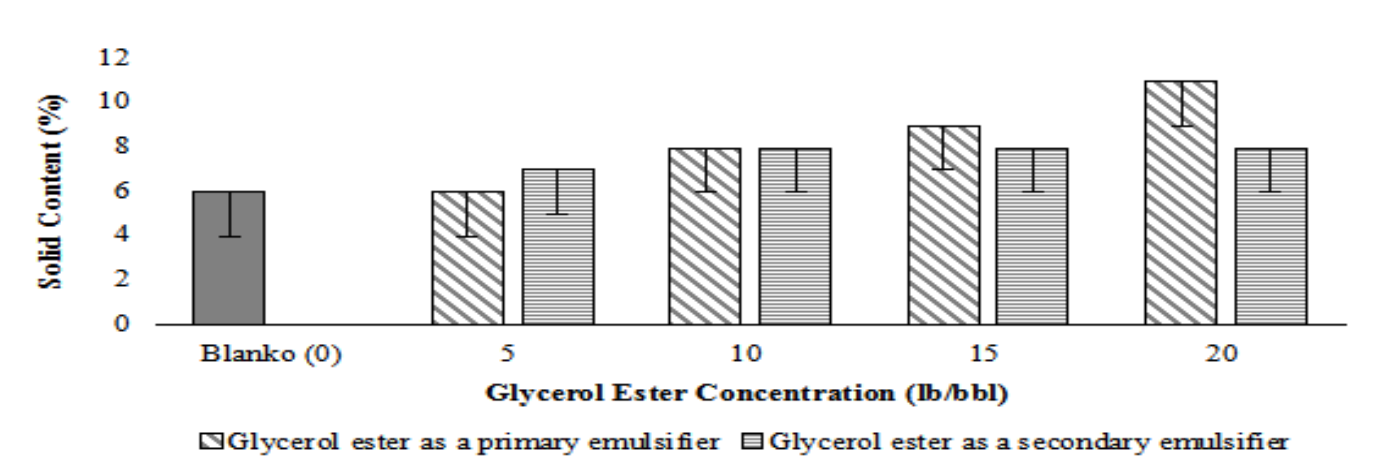

Figure 8:- Relationship between glycerol ester concentrations with solid content

The figure above shown that the solid content will increases with increasing concentration of glycerol ester. Analysis of variance $(\alpha=0.05)$ showed that the addition of glycerol ester as primary emulsifier at $5 \mathrm{lb} / \mathrm{bbl}, 10 \mathrm{lb} / \mathrm{bbl}$ and $15 \mathrm{lb} / \mathrm{bbl}$ is not significantly different effect than the blank. Concentration of $20 \mathrm{lb} / \mathrm{bbl}$ has significant effect on the solid content when compared to the blank. In the secondary emulsifier, the addition of glycerol esters has no significant effect on the solid content at level of significance 0.05. Increasing the value of solid content in mud formulation with the addition of glycerol esters caused by impurities by Material Organic Non Glycerol (MONG). Pure glycerol that used as raw material for the manufacture of glycerol ester is still contains approximately $1.17 \%$ MONG (Rafi 2015). MONG content will affect the solids content of the mud formulation. Solid content in the drilling mud must be controlled well because if it is too high will slowing the mud flow, difficulty to control mud rheology properties, equipment wearing and expensive treatment cost. Required mud density in oil based drilling is around $6 \%-12 \%$.

\section{Mud Cake:-}

Mud cake is large particles stuck on the surface and forms a rock layer. Good mud cake is thin (to reduce the likelihood of drill pipe pinching), strong (to maintain the stability of the drill holes) and solid (to control excessive filtrate that enters the formation). Thick mud cake will clamp the drilling pipe that make difficult to be lifted and rotated while filtrate that enter into the formation will break formation and can formation damage. The addition of glycerol ester at certain concentrations give mud cake ranges between $0.061-0.1183$ inchies for glycerol esters as primary emulsifier and $0.078-0.157$ inchieson glycerol ester as secondary emulsifier. Figure 9 shows the effect of glycerol ester addition as primary and secondary emulsifier. 


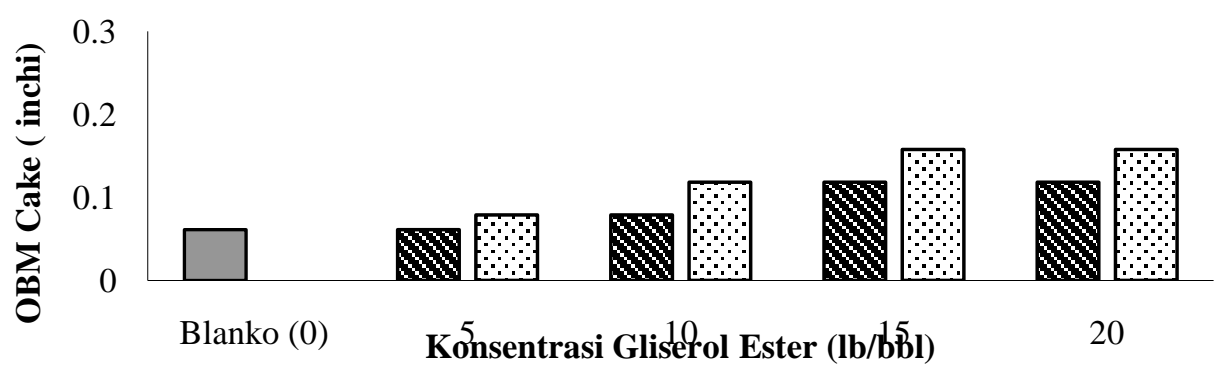

\$Glycerol ester as primary emulsifier @Glycerol ester as secondary emulsifier

Figure 9:- Relationship between glycerol ester concentration with Mud Cake

The figure show that the addition of glycerol esters causes increase in mud cake produced from the mud formula. Analysis of variance showed that glycerol ester as primary emulsifier has no significant affect at concentrations of 5 $\mathrm{lb} / \mathrm{bbl}$ compared to the blank, while concentrations of $10 \mathrm{lb} / \mathrm{bbl}, 15 \mathrm{lb} / \mathrm{bbl}$ and $20 \mathrm{lb} / \mathrm{bbl}$ gives show significant effect than the blank at 0.05 . For secondary emulsifier, concentration of $5 \mathrm{lb} / \mathrm{bbl}$ and $10 \mathrm{lb} / \mathrm{bbl}$ is not significantly different than the blank formulation, while at concentration of $15 \mathrm{lb} / \mathrm{bbl}$ and $20 \mathrm{lb} / \mathrm{bbl}$ is significantly different at 0.05 . Mud cake is related to the presentation of solids, chemical properties and mud stability. Increased mud cake on mud formulations using glycerol ester emulsifiers is associated with mud solids content which also increased with the addition of glycerol ester. Large viscosity and density in glycerol esters is also affect the thickness of mud cake produced in the mud formulation. If the mud cake wall is not too thick, it can prevent the loss of mud into the formation, because filtrate that left in the wall formation will stop the flow of drilling fluid. Meanwhile, if the walls are too thick, it can cause pinching of the drilling pipe (sticking). To overcome the cake thickness, it can be added chemicals substance to improve the distribution of solids in the mud to reduce filtrate loss as controller and reinforce mud cake.

\section{Conclusion:-}

Glycerol ester is one product of palm oil derivatives that can be used more widely as drilling fluid emulsifier in oil drilling industry. This research shows that the glycerol esters as primary and secondary emulsifier meets the requirements according to formulations test with blanks as benchmark. The obtained concentration of glycerol esters according to the performance test is glycerol esters at concentration $5 \mathrm{lb} / \mathrm{bbl}$ for primary emulsifier and a secondary emulsifier. Performance tests carried out on glycerol ester is include density test, viscosity, gel strength, plastic viscosity, yield point, electrical stability, oil water ratio, excess lime, the percentage of water and oil, and HPHT filtrate at temperatures of $350^{\circ} \mathrm{F}$ and pressure 650 psi. All the test is based on API standards and show that glycerol esters has good performance as emulsifier in oil drilling mud formulation.

\section{Acknowledgement:-}

The author would like to thank to PT ELNUSA, TBk on the support in the form of OBM material and suggestions for research, Education Fund Management Institute for research funds and laboratory analysts in SBRC LPPM - IPB for its assistance in the implementation of this study.

Refferences:

1. Adams N. J., Charrier T., (1985) Drilling Engineering, Complete Well Planning Approach. Tulsa : Penn Well Publishing Company.

2. Amoco Production Company (1994) Drilling Fluids Manual. Texas: Amoco Production Company.

3. [API] American Petroleum Institute. 2003. Specification for drilling-fluid materials - Specification 13A. Washington DC: American Petroleum Institute.

4. [API] American Petroleum Institute. 2004. API Recommended Practice Standard Procedure for Field Testing Oil-Based Drilling Fluids 13B-1 3rd Edition: Exploration and Production Departement. Washington DC: American Petroleum Institute.'

5. [API] American Petroleum Institute. 2005. API Recommended Practice For Field Testing of Oil Based Drilling Fluids13b-2 Fourth Edition, March (2005) Washington DC: American Petroleum Institute.

6. Nedham M., D., (1995) Drilling Engineering Workbook: A distributed learning course. United State of America: Baker Hughes INTEQ. 
7. Hou P.W., Yun-Peng Z., David G. (2003) Emulsifierforoil-based drilling fluid. US Patent No. 2003/0130135 A1

8. KendelE.,M. (2012) Synthesis and performance of glycerol ester-based nonionic surfactants. Der ChemicaSinica. 2 (3): 88-98

9. Moore P.,L. (1974) Drilling Practice Manual. Tulsa : Penn Well Publishing Company.

10. Muller H., Maker D., Herzog N. (2012) Oligoglycerol Fatty Acid Ester Thickeners for Oil-Based Drilling Fluids. US Patent No. 8153562 B2.

11. Noureddini H., Zhu D. (1997) Kinetics of transesterification of Soybean oil. JAOCS 74 (11): 1457-1463.

12. Othmer K. 1990. Encyclopedia of chemical technology, 4th edition. Volume 1: A to Alkaloids. John Wiley \& Sons Inc.

13. Pouilloux Y.S., Abro C., Vanhove J., Barrault. (1998) Reaction of glycerol with fatty acids in the presence of ion-exchange resins Preparation of monoglycerides. Journal of Molecular Catalysis A: Chemical 149 (1-2): 243-254

14. Perrin D.D., Armarego W.L.F. (1988) Purification of Laboratory Chemicals. Oxford: Pergamon Press

15. Rafi M. (2015) Purity enhancement of $80 \%$ palm oil glycerol using vacuum distillation scale 25 litre [Thesis]. Indonesia: Bogor Agricultural University.

16. Ryen C. (2011) Composition and Properties of Drilling and Completion Fluids. Amsterdam: Elsevier.Inc

17. Soares V.L.P., Elizabeth R.L., Rodrigues Jr. J de A., Batista L. N., Nascimento R.S.V. (2011) New Applications for Soybean Biodiesel GlycerolProf. Tzi-Bun Ng (Ed.). In Tech: Croatia

18. Westfechtel A., Diana M., Heinz M. (2012) Oligoglycerol fatty acid ester additives for water-based drilling fluids. US Patent No. 8148305. 